\title{
Evaluating the potential of freeze-thaw damage in internally insulated masonry under climate change using different models
}

\author{
Sahar Sahyoun ${ }^{1}$, Hua $\mathrm{Ge}^{2}$, Maurice Defo ${ }^{3}$, and Michael Lacasse ${ }^{4}$ \\ ${ }^{1}$ Ph.D. Student, Concordia University, Montreal, Canada and Research Assistant, National Research \\ Council Canada, Ottawa, CA; s_sahyo@live.concordia.ca ; Sahar.Sahyoun@nrc-cnrc.gc.ca \\ ${ }^{2}$ Associate Professor, Concordia University, Montreal, Canada; Hua.Ge@concordia.ca \\ ${ }^{3}$ Associate Research Officer; Construction Research Centre, National Research Council Canada, \\ Ottawa, \\ $\mathrm{CA}$; \\ Maurice.Defo@nrc-cnrc.gc.ca \\ ${ }^{4}$ Senior Research Officer and Team lead, Façade Systems and Products, Construction Research \\ Centre, National Research Council Canada, Ottawa, CA; Michael.Lacasse@nrc-cnrc.gc.ca
}

\begin{abstract}
To mitigate the effects of climate change, higher insulation levels in buildings are mandated by the National Energy Code for Buildings. However, increased insulation levels within building envelopes may lead to a greater risk of moisture problems. With a changing climate, higher rainfall intensity, stronger winds and more storms are expected, which may increase wind-driven rain loads on façade and risks for rain penetration damages of building envelopes. This paper aims to present results of the effects of climate change on the freeze-thaw damage risk of internally insulated brick masonry walls of buildings in different Canadian cities, using different freeze-thaw models. Freeze-thaw damage was evaluated using different freeze-thaw models. Simulations were performed using DELPHIN 5.9.4. Results showed potential risk to freeze-thaw in Montreal and Vancouver after retrofit. Under climate change, Winnipeg has the lowest risk to frost damage, though damage functions showed an increase in the level of severity. Comparing the results of different models under a changing climate, the damage functions seemed in a good agreement for most of the cases, except for the Indicative Freeze-Thaw Cycles (IFTC) evaluated in St-Johns. This model counts the number of freeze-thaw cycles based on short duration of freezing and thawing and therefore does not consider longer freeze-thaw period.
\end{abstract}

\section{Introduction}

Brick masonry is the most conventional way brick was used in older Canadian construction for centuries. When energy was inexpensive, buildings with thick solid brick walls allow the masonry mass to resist water penetration and offer a barrier between interior and exterior environments. However, the need to save energy has led to thermally insulated buildings. Due to historical and aesthetical values of the building stock, interior retrofitting seems the only option, despite increased durability risks. This durability problem raised concerns about the proper application of interior insulation [1]. Canada Mortgage and 
Housing Corporation inspected the potential energy saving from retrofitting the existing Canadian residential buildings in different provinces in Canada. The study concluded that among all categories the potential energy savings of retrofitting Pre-World War II homes will be greater than other types of houses [2-3].

Frost damage is one of the main reasons threatening durability of the structures in cold climates. Previous research has shown that under a changing climate, higher rainfall intensity, strong winds, and more frequent storms are expected, which may increase winddriven rain loads on façade and risks for rain penetration damages of building envelopes. On the other hand, increased solar radiation and air temperature may increase the drying potentials. For instance, a study led by Grossi et al. [4] on the long-term freeze-thaw risk of porous materials for European cities has concluded that the frost damage on the masonry used in monumental buildings would tremendously decrease under future climates.

Research in the past has introduced several damage functions to quantify the subsequent risk of deterioration. The most traditional way of quantifying the risk of freeze-thaw damage is through counting the number of possible freeze-thaw cycles. The freeze-thaw index is described as the number of cycles when temperatures fluctuate between the freezing and thawing point of envelope materials that are almost at the moisture saturation level, $\mathrm{RH}_{\text {critical }}$ [5]. Another damage function developed by Koci et al. [6] is the winter index (WI), which evaluates the risk of frost damage based on calculating the level of severity in the case that RH is above the critical level and concurrently temperature falls below its freezing value. Similarly, the Time-of-Frost (TOF) function [7] evaluates the risk of frost damage based on calculating the number of hours during the year when conditions are favorable for ice formation. According to [8], the RH is not a good measure for freeze-thaw damage, because the sorption isotherm of brick materials is very steep in the region in which FT damage is possible, and therefore the RH would typically be above $99 \%$ regardless of which critical MC is selected. Koci et al. proposed modified versions of the winter index (MWI) [6] and (TOF) [7], which utilise hourly values of MC instead of RH, and calculates the level of severity in the case that $\mathrm{MC}$ is higher than the critical level. Another damage function introduced by Koci et al. [9] is the amount of frozen water (AFW), which assumes that the whole amount of moisture found in the material at temperature below its critical level is vulnerable for ice formation. Koci et al. also used the number of (IFTC) to estimate the number of FT cycles [9]. A FT cycle is counted only if freezing takes at least 4 hours, followed by at least 2 hours of thawing period [10]. The $\mathrm{MC}_{\text {crit }}$ corresponds to $99 \% \mathrm{RH}$ of the material where the investigation is placed, whereas, the $\mathrm{T}_{\text {crit }}$ is assumed to be equal to zero [11-13].

This paper evaluates the hygrothermal performance of the brick masonry wall before and after retrofit and analyses the level of severity of freeze-thaw damage under climate change using the modified damage functions MWI and TOF, as well as the AFW and the IFTC models.

\section{Methodology}

\subsection{Weather data}

For the investigation of the frost loads in Canada, five cities having different climatic characteristics were selected (Table 1). Weather data were provided by the National Research Council of Canada (NRC). A continuous time-series of hourly climate data spanning 1986-2016 was prepared by collecting observations of temperature, rainfall, windspeed and direction, cloud-cover, solar radiation, and relative humidity from observational databases maintained by Environment and Climate Change Canada, and filling-in data gaps 
using bias-corrected Climate Forecast System Reanalysis estimate of these variables. Data collected include hourly values of climate conditions for 31 consecutive years (1986 2016). The first 10 years $(1986-1996)$ are considered as historical data, while the last 10 years $(2006$ - 2016) represented the future data for this study. Moisture index (MI) [14] have been chosen as the indices for selecting the reference years. A two-year period was chosen for simulations. The first year was chosen as the year that was characterized by the median MI value of the selected years and the second year was chosen as the one with the highest MI. Consequently, different moisture reference years were obtained for each city (Figure 3).

\subsection{Masonry wall structure}

A solid masonry wall commonly designed during the Pre-World War II is chosen as the base wall assembly [2-3]. The base wall is retrofitted by adding $140 \mathrm{~mm}$ XPS board, $38 \mathrm{~mm}$ $\mathrm{x} 50 \mathrm{~mm}$ steel stud and gypsum board, as shown in Fig. 1 .

Materials and their properties were all obtained from the NRC hygrothermal material property database [15]. The brick masonry used have a density $(\rho)$ of $1900 \mathrm{~kg} / \mathrm{m}^{3}$, a specific heat capacity $(\mathrm{Cp})$ of $800 \mathrm{~J} / \mathrm{kgK}$, a thermal conductivity $(\lambda)$ of $0.5 \mathrm{~W} / \mathrm{mK}$ and a maximum MC of $112 \mathrm{~kg}_{\text {(water) }} / \mathrm{m}^{3}$ (dry mat).

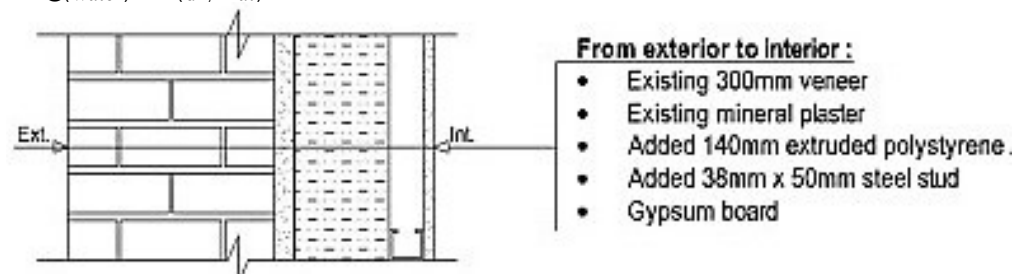

Fig. 1. Solid masonry wall retrofit solution [2-3].

\subsection{Wall orientation}

Using the free wind-rose chart, the wall orientation for each location was selected as the direction in which the rainfall frequency is highest (See Table 1).

Table 1. Characteristics and wall orientation for five Canadian cities

\begin{tabular}{|c|c|c|c|c|c|c|c|}
\hline \multirow[b]{2}{*}{ City } & \multirow[b]{2}{*}{ Lat $^{1}$} & \multirow[b]{2}{*}{ Long $^{2}$} & \multirow[b]{2}{*}{ HDD $^{3}$} & \multirow[b]{2}{*}{$\mathrm{MI}^{4}$} & \multirow[b]{2}{*}{$\mathrm{CZ}^{5}$} & \multicolumn{2}{|c|}{ Wall orientation } \\
\hline & & & & & & $\begin{array}{c}\text { Historical data } \\
(1986-1996)\end{array}$ & $\begin{array}{c}\text { Future data } \\
(2006-2016)\end{array}$ \\
\hline Calgary & 51.05 & -114.07 & 5000 & 0.37 & $7 \mathrm{~A}$ & North & South \\
\hline Montreal & 45.5 & -73.56 & 4200 & 0.93 & 6 & SSE & South \\
\hline St-Johns & 47.55 & -52.71 & 4800 & 1.41 & 6 & South & South \\
\hline Vancouver & 49.28 & -123.12 & 3100 & 1.93 & 5 & ESE & East \\
\hline Winnipeg & 49.9 & -97.14 & 5670 & 0.58 & $7 \mathrm{~A}$ & South & South \\
\hline
\end{tabular}

${ }^{1}$ Latitude, ${ }^{2}$ Longitude, ${ }^{3}$ Heating Degree Days, ${ }^{4}$ Moisture Index, ${ }^{5}$ Climate Zone

\subsection{Initial conditions}

In heavy masonry significant quantities of water can persist in construction layers and it could take considerable time for these initial conditions to cease affecting the model. To eliminate the impact of assumed conditions, the retrofitted wall was modeled for several years (cyclical year) in each city, with no WDR effect, until the initial conditions no longer impact the variation in water content throughout the years. Initial T and RH were set as the 
average value of ambient air temperature and $\mathrm{RH}$ in January (the starting point of the simulations). Once a steady cyclical pattern is observed in the wall, the moisture profile is exported and used for the initial moisture profile conditions [16].

\subsection{Boundary conditions}

Internal boundary conditions - A previous study, done by Cornick and Kumaran [17] on the accuracy of four different models predicting the indoor RH, indicates that ASHRAE 160 [18] intermediate model is the most precise compared to the European Indoor Class Model, the British Research Establishment (BRE) model and ASHRAE 160 simple method. Therefore, the indoor RH was computed for each city using the ASHRAE intermediate method. Also, according to ASHRAE, the indoor temperature was calculated using the indoor design temperature for heating only.

External boundary conditions - Delphin 5 uses Boltzmann model to calculate the longwave radiation. The required emission coefficient of the building surface is 0.9 . As for the reflection coefficient of the surrounding ground (albedo) and the absorptance coefficient of the building surface, they are equal to 0.2 and 0.6 respectively. The WDR was computed for each city using the method described by Straube and Brunett [19] for low rise buildings.

\subsection{Simulations}

Two sets of simulations were performed using hygrothermal simulation program DELPHIN 5, v5.9.4. The first set comprises simulations under historical loads of the base and the retrofitted walls. Whereas, the second set were carried out under historical and future climatic conditions for the retrofitted wall only. No air and moisture leakage source were assumed. Simulations were executed over a two-year period for five Canadians cities. However, only the second simulated year's results are used for analysis. The point of investigation was placed at a depth of $5 \mathrm{~mm}$ of the brick surface.

A fine variable discretization, with a minimum element width of $0.25 \mathrm{~mm}$ and a maximum of $15.8 \mathrm{~mm}$ was used to set up the meshing of the brick, to generate high resolution results at the designated critical location. However, for the rest of materials, a variable discretization with a minimum width of $1 \mathrm{~mm}$ was assigned. Thus, the total number of elements of the base and the retrofitted case was 101 and 159, respectively.

\section{Results and discussion}

Figure 2 shows the increase in $\mathrm{MC}$ at $5 \mathrm{~mm}$ from the masonry surface before and after retrofit. It is observed in all simulated cities that the brick masonry has higher moisture content when retrofitted, which indicates a potentially greater frost damage risk. The critical MC above which brick becomes susceptible to frost damage is set to $99 \% \mathrm{RH}$ as suggested by [7]. 
a)

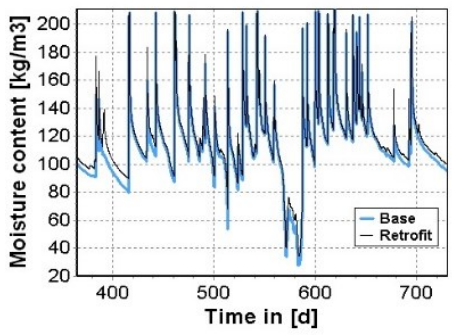

b)

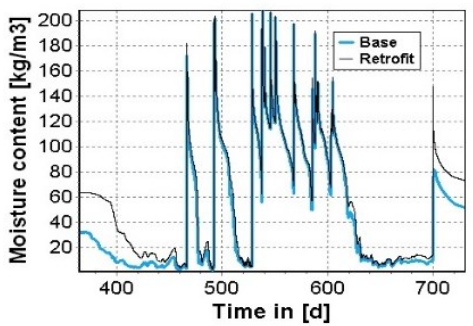

Fig. 2. Moisture content at point of investigation before and after retrofit for a) Montreal and b) Winnipeg

Table 2 shows the number of all computed damage functions for both the base and the retrofitted cases for the historical climatic conditions. The overall performance of all damage functions was in agreement; after interior insulation was added all damage function values increased, indicating a higher potential of freeze-thaw to occur.

No information is found in the literature concerning a threshold value over which freeze-thaw damage can happen for most damage functions; their values describe the change in the level of severity under climate change. Netinger et al. [20] considered the brick resistant to freezing/thawing cycles if the signs of damage are not visible after 25 cycles of FT. Assuming that, Calgary, St-Johns and Winnipeg will have no risk of FT damage. However, Montreal and Vancouver might be at risk of FT, since their IFTC value was found 41 and 28 cycles, respectively.

Table 2. Comparison of frost damage models results before and after retrofit for five Canadian cities.

\begin{tabular}{c|cccccccccc}
\multicolumn{4}{c}{ CALGARY } & \multicolumn{2}{c}{ MONTREAL } & \multicolumn{2}{c}{ ST-JOHNS } & \multicolumn{2}{c}{ VANCOUVER } & \multicolumn{2}{c}{ WINNIPEG } \\
\hline & Base & Retrofit & Base & Retrofit & Base & Retrofit & Base & Retrofit & Base & Retrofit \\
MWI & 21 & 51 & 160 & 282 & 657 & 876 & 21 & 37 & 0 & 5 \\
TOF & 360 & 614 & 1659 & 2263 & 2898 & 3178 & 278 & 463 & 5 & 107 \\
\hline IFTC & 14 & 24 & 38 & 41 & 10 & 11 & 14 & 28 & 1 & 4 \\
\hline AFW & 22.6 & 41.2 & 110 & 155.6 & 260.3 & 302.6 & 22.1 & 37.9 & 0.3 & 6.5 \\
\hline
\end{tabular}

The second set of simulations intended to evaluate the impact of future climate change on the durability of brick masonry against freeze-thaw damage. Results of all computed FT damage functions for assumed historical and future climates are shown in Figure 3.
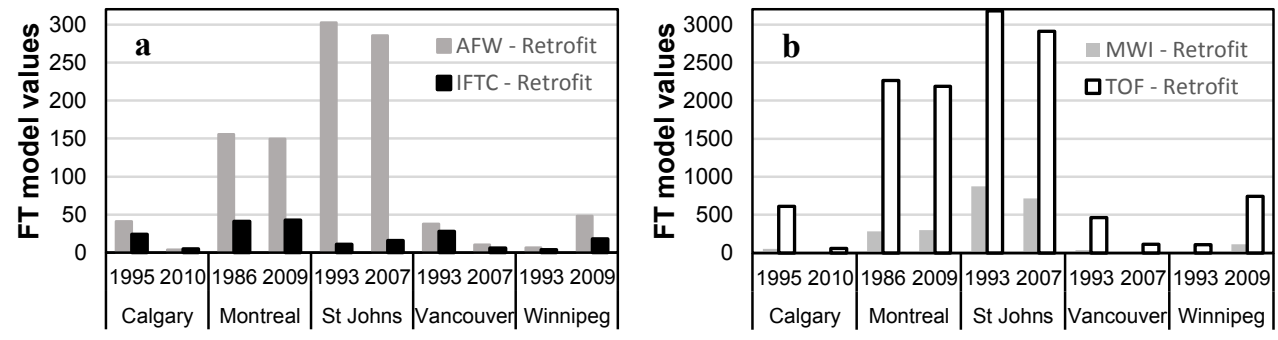

Fig. 3. Comparison of FT models values in different Canadian cities under climate change; where a) AFW and IFTC, and b) MWI and TOF 


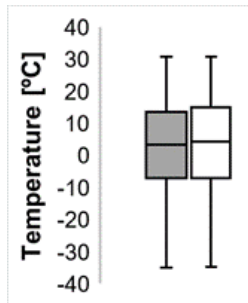

a $\square 1993 \square 2009$

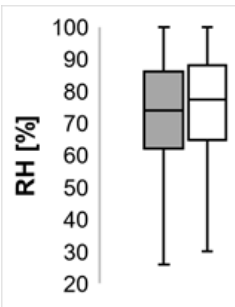

b $\square 1993 \square 2009$
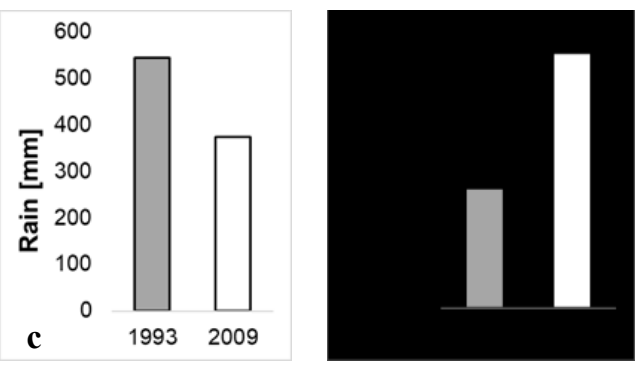

Fig. 4. Winnipeg climate variables: a) yearly average of $T, b)$ yearly average of $R H, c$ ) annual amount of rainfall, and d) number of rain events in year 1993 and 2009

A general observation of the results shows that the FT risks are reduced for Calgary, StJohns and Vancouver, remained unchanged in Montreal, and increased in Winnipeg. Figure 4 represents climatic loads in Winnipeg for the simulated historical year (1993) and assumed future year (2009). The analysis of the weather data for Winnipeg shows an increase in average $\mathrm{RH}$ of about $4 \%$ in 2009 . Moreover, while the amount of annual rain is higher in 1993 than in 2009 (537.2 mm and $374 \mathrm{~mm}$, respectively), 2009 has $5 \mathrm{~mm} / \mathrm{hr}$ of rain at temperature below freezing point and only $3 \mathrm{~mm} / \mathrm{hr}$ in 1993. And even though 1993 experience higher amount of rain, 2009 shows more frequent rain events (Figure 4.b). Moreover, some discrepancies in the analyzed functions' values were noticed for St-Johns. All functions show a decrease in values except for IFTC which increase from 11 cycles in 1993 to 18 cycles in 2007. This could be explained by means of IFTC definition, which takes into account small duration of freezing and thawing period and therefore does not consider longer FT period.

\section{Conclusion}

This study investigates the impact of climate change on the durability of typical masonry wall assemblies retrofitted with interior insulation in 5 Canadian cities. The durability of solid masonry wall was assessed based on the potential to freeze-thaw damage risk at $5 \mathrm{~mm}$ from brick exterior surface. The risk to FT increased by adding interior insulation to the massive base wall. Results indicated that Winnipeg has the lowest risk to frost damage, though damage functions showed an increase in the level of severity over a changing climate. Comparing the results of different models under climate change, the damage functions seemed in a good agreement for most of the cases, except for St-Johns where the only different function was the IFTC. This model counts the number of FT cycles based on short duration of freezing and thawing and therefore does not consider longer FT period. One limitation to this paper is that it compared a short period of time to make a statement about the effect of climate change, which might not be a good representation of future years. The impact of projected future climates on the frost-damage of internally insulated brick walls will be carried out and reported later.

\section{References}

1. J. Straube, C. Schumacher, P. Mensinga, Buildings XI Conf. ASHRAE (Clearwater, 2010)

2. CMHC. Near Net Zero - Energy Retrofits for houses (Vancouver, 2011)

3. A. Sehizadeh, H. Ge, Bldg. and Env. 97, 111-125 (2016)

4. C. M. Grossi, P. Brimblecombe, I. Harris. Sc. Of the Tot. Envir. 377, 273-281 (2007)

5. P. Mukhopadhyaya, K. Kumaran, M. Nofal, F. Tariku, D. Van Reenen, the 7th symposium on building physics in the Nordic countries (Iceland, 2005) 
6. V. Koci, J. Madera, J. Fort, J. Zumar, M. Pavlikova, Z. Pavlik, R. Cerny. The Sc. Wor. Jour. (2014) 7. K. Calle and N. Van Den Bossche, International Conference on Durability of Buildings Materials and Components (Ghent, 2017)

8. J. Straube, C. Schumacher. PhD diss. (Waterloo, 1991)

9. J. Koci, J. Madera, M. Keppert, R. Cerny, Cold Reg. Sc. And Tech. 135, 1-7 (2017)

10. J. Madera, J. Kocí, R. Cerný. 6th International Advances in Applied Physics and Materials Science Congress \& Exhibition (Prague, 2017)

11. A. Al-Omari, K. Beck, X. Brunetaud, Á. Török and M. Al-Mukhtar, Eng. Geo. 185, 71-80 (2015)

12. A. Al-Omari, X. Brunetaud, K. Beck and M. Al-Mukhtar, Env. Earth Sc. 71, 3977-3989 (2014)

13. D. Ponziani, E. Ferrero, L. Appolonia and S. Migliorini, Jour. Of Cul. Her.13, 462-468 (2012)

14. S. Cornick, W. A. Dalgliesh, Jour. of Therm. Env. and Bldg. Sc. 27, 151-178 (2003)

15. M.K. Kumaran. ASHRAE Research Project RP-1018, Final Report (NRC, 2002)

16. J. Little, B. Arregi. ASHRAE Transactions 121 (2015)

17. S. M. Cornick, M. K. Kumaran, Jour. Of Bldg. Phys. 31, 243-268 (2008)

18. ANSI, ASHRAE 160. Criteria for Moisture-Control Design Analysis in Buildings (Atlanta, 2016)

19. J. Straube, E. Burnett, International Building Physics Conference (Eindhoven, 2000)

20. I. Netinger, M. Vracevic, J. Ranogajec and S. Vucetic, Grad. 66, 197-209 (2014) 